\title{
A DINÂMICA ÉTICA DAS MÁQUINAS EM INTELIGÊNCIA ARTIFICIAL E O NOVO PAPEL DO PROFESSOR DE FILOSOFIA
}

\author{
THE ETHICAL DYNAMICS OF MACHINES IN ARTIFICIAL INTELLIGENCE AND \\ THE NEW ROLE OF THE PHILOSOPHY PROFESSOR
}

\begin{abstract}
Newton Silva Duarte
RESUMO: A ética computacional considera uma dinâmica baseada em técnicas, valores e princípios aceitos como certo ou errado para nortear a conduta moral no desenvolvimento de algoritmos de inteligência artificial. O aprendizado por reforço é um modelo de inteligência artificial que se dispõe a resolver um problema proposto em um ambiente incerto e complexo baseado em uma sequência de decisões em que não importam os meios utilizados para atingir o fim. $\mathrm{O}$ algoritmo é penalizado ou recompensado pelas ações que executa. No entanto ele busca sempre a maior recompensa possível. A consideração do impacto social, ético e moral neste cenário cibernético. O dilema da liberdade ou do controle da inteligência artificial nos sistemas autônomos. Lidando com a discriminação algorítmica com a humanidade e suas idiossincrasias diante do poder computacional exponencial e sem limites. O devir da anunciada singularidade tecnológica. Mitigando conflitos entre a inteligência das coisas e a consciência humana para tornar a vida mais significativa e menos complexa na modernidade líquida. Uso das melhores habilidades que a tecnologia dispõe para trazer sentido a vida, fazendo a interação entre os homens e as coisas mais humana, natural, cognitiva, sustentável e socialmente responsável. A importância e a influência do pensar filosófico na edificação de um conhecimento colaborativo, ético e moral que precede a parametrização e definição das métricas e métodos dos algoritmos de Inteligência artificial incorporados nas coisas e nas redes em benefício da sociedade do conhecimento. O papel do professor de filosofia neste novo cenário.
\end{abstract}

Palavras-chave: Ética Computacional. Inteligência Artificial. I.A. Professor de Filosofia.

ABSTRACT: Computational ethics considers dynamics based on techniques, values, and principles accepted as right or wrong to guide moral conduct in the development of artificial intelligence algorithms. Reinforcement learning is an artificial intelligence model that is willing to solve a problem proposed in an uncertain and complex environment based on a

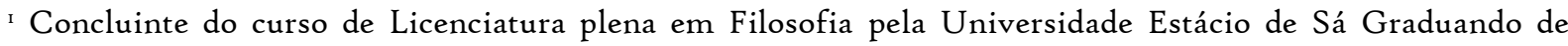
Engenharia da Computação na UNINTER, pós graduando do curso MBKM - Master in Business and Knowledge Management no CRIE - Coppe/UFRJ. E- mail para divulgação. E-mail: nduarte@ieee.org.
} 
sequence of decisions in which the means used to reach the end do not matter. The algorithm is penalized or rewarded for the actions it performs. However, it always seeks the highest possible reward. Consideration of the social, ethical, and moral impact in this cyber scenario. The dilemma of freedom or control of artificial intelligence in autonomous systems. Dealing with algorithmic discrimination with humanity and its idiosyncrasies in the face of exponential and limitless computational power. The coming of the announced technological singularity. Mitigating conflicts between the intelligence of things and human consciousness to make life more meaningful and less complex in liquid modernity. Use of the best skills that technology has to bring meaning to life, making the interaction between men and things more human, natural, cognitive, sustainable, and socially responsible. The importance and influence of philosophical thinking in the construction of collaborative, ethical, and moral knowledge precedes the parameterization and definition of the metrics and methods of the Artificial Intelligence algorithms incorporated in things and networks for the benefit of the knowledge society. The role of the philosophy professor in this new scenario.

Keywords: Computer Ethics. Artificial Intelligence. A.I. Philosophy Professor.

\section{INTRODUÇÃO}

O principal objetivo deste artigo é identificar os principais impactos éticos e morais impostos pela Inteligência Artificial e a qual importância fundamental da dimensão humana para o questionamento e enfrentamento das aparentes impossibilidades presentes, ferramentas, tecnologias exponenciais e transformações digitais.

Pretende-se responder se a formação do licenciado em filosofia, até então tendo a sala de aula como único caminho profissional viável, é adequada para a edificação de novos conhecimentos e construir questionamentos a partir da interação com a sociedade contemporânea, na colaboração com engenheiros e demais profissionais especialistas, visando construir um diálogo amplo, generalista e sustentável diante de uma nova realidade tecnológica desvelada pela Inteligência Artificial.

Como lidar com as possíveis consequências e mitigar o que foi preconizado pelos principais autores de ficção científica e cientistas sobre um provável futuro de poder computacional em rede, exponencial e ilimitado. Máquinas construindo máquinas que podem subjugar, discriminar ou excluir grupos por especificidades ou características retratam a relevância do tema para a sociedade, empresas, governos e demais interessados. 
Este cenário escatológico retrataria um futuro possível, capaz de viabilizar novas guerras, eliminar a vida como conhecemos e nos aproximar do apocalipse? Neste artigo pretende-se justificar que o futuro desejado e mais provável fomente novas revoluções científicas, conduza o planeta a um novo iluminismo, a um modelo não mais antropocêntrico, mas biocêntrico, já que sem a natureza não há humanidade. Alguns autores e futurólogos afirmam que viveremos uma era de abundância, progresso e longevidade humana nunca antes vista na história da civilização. A tecnologia e a inovação seriam as ferramentas adequadas para benefício da sociedade e para a preservação dela?

Para o desenvolvimento dos objetivos com consistência analítica e argumentativa, este artigo tem como base uma pesquisa exploratória, adotando como metodologia uma abordagem qualitativa, construída a partir de análises conceituais e estudo comparativo das obras de diferentes autores em uma revisão bibliográfica para subsídios ao tema da pesquisa, seus objetivos, impactos e consequências.

\section{ATRAVÉS DOS TEMPOS ENTRE O CERTO E O ERRADO}

A ética é um campo da filosofia, que também é conhecida por filosofia moral. Ela se preocupa com o que é moralmente bom ou ruim e moralmente certo ou errado. A ética se aplica a qualquer sistema, teoria de valores ou princípios morais.

Segundo Singer (2021), tradicionalmente a ética se referia ao estudo filosófico da moralidade, sendo esta última um conjunto mais ou menos sistemático de crenças, geralmente mantidas em comum por um grupo, sobre como as pessoas devem viver. Mais tarde, o termo ética foi aplicado a códigos morais ou sistemas de valores particulares e mais restritos. Atualmente ética e moralidade são usadas quase que alternadamente em muitos contextos, mas o nome do campo da filosofia continua sendo ética.

A ética não é uma ciência social. Muitas vezes é entendida como equivalente a moralidade, mesmo que a sociedade contemporânea tenha uma tendência a tolerar uma moral relativa. Ela poderia ser estudada como uma construção social, um fenômeno sócio psicológico ou até histórico, sendo neste caso um objeto de estudo sócio científico e não uma ciência social em si. Entendida como o estudo filosófico dos conceitos morais, a ética é um 
ramo da filosofia que consiste nas questões fundamentais da tomada de decisão prática. Suas principais preocupações incluem a natureza do valor final e os padrões pelos quais as ações humanas podem ser julgadas certas ou erradas (SINGER, 202I).

\section{I NA ANTIGUIDADE}

Aristóteles (1987), considerado o pai da ética da virtude na antiguidade, atribui a origem da ética à primeira virada antropológica da história, quando o homem assumiu a responsabilidade por suas ações, que até então eram atribuídas aos deuses e começou a refletir sobre a melhor maneira de conviver na pólis. Em seu tratado ético mais importante, ética a Nicômaco, ele classifica o que é verdadeiramente virtuoso e o que é erroneamente pensado como tal, criando o conceito do meio dourado, que seria o caminho entre a auto indulgência e a auto renúncia, pregando que o melhor caminho seria o do meio. E para isso, seria necessário fazer a distinção entre sabedoria e prática para se manter longe dos extremos. Alguns autores associam o início da ética com a introdução dos primeiros códigos morais, já que a maioria das sociedades humanas tinham alguma forma de mito para explicar a origem da moralidade. O código de Hamurabi e a bíblia Hebraica seriam exemplos conhecidos destes códigos morais.

Platão (1999), em seu diálogo Protágoras fez um relato mítico de como Zeus teve pena dos humanos infelizes, que não conseguiam enfrentar criaturas mitológicas e outras bestas. Para compensar estas deficiências, Zeus deu aos humanos um senso moral e um conceito de lei e justiça, mesmo que somente de origem divina, para que pudessem viver em comunidades maiores e cooperarem um com os outros.

A vida social requer restrições de comportamento. Nenhum grupo pode se manter unido se os seus membros fizerem ataques frequentes e desenfreados uns aos outros. $O$ historiador grego Heródoto afirmava que cada povo pensa melhor o seu código moral de acordo com a sua cultura, e isso explica ações que podem ser apreciadas por um povo e condenadas por outro, originando assim o relativismo moral. Ele argumentou ainda que embora o conteúdo particular das regras morais de cada povo possa variar, deve haver alguns tipos de regras para que a vida seja tolerável (SINGER, 202I). 


\subsection{NO RENASCIMENTO}

Com o renascimento, que caracterizou mais uma virada antropológica na história, o protagonista voltou a ser o homem, e não mais o Deus todo poderoso que todos temiam no medievo. Jacob Burckhardt (2009), em sua obra A Cultura do Renascimento na Itália ensaiou a história política, religiosa e cultural dos séculos XIV ao XVI que culminou no individualismo moderno e ilustra este momento que retomou a importância da filosofia em uma nova forma de pensar a sociedade.

Nicolau Maquiavel (I89I) em O Príncipe, ofereceu conselhos aos governantes sobre o que eles devem fazer para alcançar seus objetivos e garantir o seu poder. Seu significado para a ética reside precisamente no fato de que o conselho de Maquiavel ignora as regras éticas usuais, preocupando-se em apenas definir como são os seres humanos e como o poder é mantido, sem a intenção de julgar moralmente o estado das coisas. A citação de que "os fins justificam os meios" é erroneamente atribuída a Maquiavel, sendo seu verdadeiro autor o poeta romano Ovídio. Mas foi utilizada por Maquiavel para explicar que os governantes devem estar acima da ética (meios) para manter ou aumentar o seu poder (fins), já que o poder era o principal valor.

Thomas Hobbes (1974) em Leviatã, cunhou a famosa "Guerra de todos contra todos", em que a luta ocorreria porque cada indivíduo perseguiria racionalmente seus próprios interesses, mas o resultado não seria do interesse de ninguém. Refletiu como esta situação poderia ser evitada e constatou que as pessoas desejam sobreviver e todos podem raciocinar.

A razão leva as pessoas a buscar a paz se ela for alcançável, mas a continuar a usar todos os meios de guerra se não for. A única forma de se evitar a paz é por meio de um contrato social, no qual cada pessoa concorda em desistir de seu direito de atacar os outros em troca da mesma concessão de todos os demais. Para que o contrato social funcione, é necessário entregar seus poderes a um soberano, com poder suficiente para manter a paz e punir aqueles que a quebrariam (HOBBES, 1974).

Já Rousseau (2006), em seu Contrato Social, se contrapõe a Hobbes (1974), quando afirma que o homem nasce bom, mas como a sociedade é uma instituição regida pela política, então ela o corrompe. Na visão de Rousseau (2006), o contrato social é um acordo entre 
indivíduos para criar uma sociedade, e somente depois disso, um estado. O contrato social proposto não é um pacto de submissão, mas de associação.

Benedict de Spinoza (1973), tomou posições que contrastavam com as de Hobbes (1974), afirmando que os indivíduos e seus interesses não podem ser separados, sendo isso uma mera ilusão. Tudo que existe é um mesmo sistema, que é ao mesmo tempo natureza e Deus. Como os indivíduos fazem parte deste sistema, então estão sujeitos às suas leis racionalmente necessárias, sendo irracional desejar que as coisas fossem diferentes do jeito que são. É irracional invejar, odiar e sentir culpa, pois estas emoções pressupõem a possibilidade de as coisas serem diferentes. Assim deixa-se de sentir tais emoções, encontrase a paz, a felicidade e até a liberdade quando se compreende o sistema do qual o indivíduo faz parte.

Immanuel Kant (1974) revelou o quanto a consciência ética ocidental mudou desde a antiguidade. Sua contribuição mais distinta para a ética foi a afirmação de que as ações possuem valor moral apenas quando se faz seu dever por si só. Baseou sua ética na distinção de imperativos hipotéticos e categóricos. Qualquer ação baseada em desejos seria um imperativo hipotético. Os imperativos categóricos são os comandos da moralidade e devem se aplicar a todos os seres racionais, independentemente de seus desejos e sentimentos. Ele se opôs fortemente aos que consideram os sentimentos benevolentes ou simpáticos como a base da moralidade e ao princípio utilitário de julgar cada ação por suas consequências, criando o que ficou conhecido como a ética do dever.

Hegel (1991) forneceu uma nova abordagem para o antigo problema de reconciliar moralidade e interesse próprio. Enquanto outros aceitaram o problema como parte da natureza inevitável das coisas e procuraram formas de contorná-lo, o autor olhou para ele historicamente, vendo-o apenas como um problema em um certo tipo de sociedade. Em vez de tentar resolver o problema como ele existia em seu tempo, ele vislumbrou o surgimento de uma nova forma de sociedade na qual ele desapareceria. Desta forma, Hegel (199I) afirmou ter superado um grande problema que era insolúvel para Kant (1974). 


\subsection{FILOSOFIA, CIÊNCIA E TECNOLOGIA}

A ciência nasce a partir da metodologia científica proposta por René Descartes (1973) em seu discurso do método, fora estruturada por Francis Bacon (1976) e desenvolvida empiricamente pelo físico Isaac Newton (1974), apresentou um método composto por um conjunto de regras básicas para desenvolver uma experiência, que permitiria que qualquer pessoa que segue o método poderia alcançar os mesmos resultados. As etapas do método seriam a observação, a formulação de uma hipótese, a experimentação, a interpretação dos resultados e pôr fim a conclusão.

Thomas Kuhn (2000), em A Estrutura das Revoluções Científicas, propôs uma nova discussão do que realmente seria a ciência. Ciência normal era o que os cientistas utilizavam até então para se ater a um único paradigma para explicar os resultados de suas experiências. A revolução científica se dá na descontinuidade, quando estes resultados são frustrados ou fogem do controle, gerando uma crise, e por consequência um novo paradigma, que eventualmente abandona o anterior. Segundo Kuhn (2000), todos os paradigmas serão inadequados no que se referem a sua correspondência com a natureza, mas quando a crise aparece, a substituição do paradigma anterior por um novo é essencial para o progresso da ciência.

Os computadores se tornaram presentes nas empresas, nas residências e com aplicações nas várias áreas do conhecimento na década de 90, dando origem aos computadores pessoais e por consequência o que conhecemos como ética da tecnologia ou tecnoética, defendida por Hans Jonas (1973) e apresentado por Cupani (201I). Trata-se de uma área interdisciplinar que cuida das dimensões éticas de sistemas de informações a fim de evitar que eles sejam usados indevidamente.

Já a tecnologia, erroneamente associada a dispositivos eletrônicos, é o ramo do conhecimento que lida com a criação e uso de ferramentas técnicas e seu relacionamento com a sociedade e o meio ambiente. Ela é fundamental para o desenvolvimento humano e um meio para a compreensão da vida e da consciência humana (NEPOMUCENO, 2016).

Segundo o professor e futurista Carlos Nepomuceno (2016), frequentemente ouvimos alguém afirmar que vai se isolar no meio do mato, se desapegando e ficando longe 
de toda a tecnologia, de forma a encontrar o seu eu interior. Trata-se de uma falácia, já que para ir a este lugar é necessário um meio de transporte, que passa por estradas, de um lugar para se abrigar, de alimentos que precisam ser conservados, roupas que serão utilizadas, entre outras ferramentas que também são tecnologias.

O autor defende que o sapiens é a única "tecnoespécie”, ou seja, uma espécie que utiliza tecnologias para sobreviver e não consegue abdicar destas evoluções que tornam melhor a vida da humanidade. Ele afirma ainda que vivemos em um "tecnoplaneta", e que se não houver tecnologias, não haverá ali nenhum sapiens. E se houver tecnologias, é sinal de que houve ou há um sapiens por ali (NEPOMUCENO, 2021).

As novas tecnologias nascem para resolver problemas, mas não causam impacto direto na sociedade. Elas abrem possibilidades aproveitadas por empreendedores para transformar antigas demandas em produtos e serviços inovadores. As necessidades político sociais e econômicas são os motores que impulsionam a adoção massiva da tecnologia. Um caso prático é o conceito de "home office" e computação em nuvem, que já estavam disponíveis há tempos, mas devido a pandemia de COVID-19, tornaram-se mandatórios para permitir que as pessoas continuassem a trabalhar, estudar, se reunir e até se cuidar à distância (NEPOMUCENO, 2021).

Diante do exposto, a tão difundida transformação digital, que pretendia inaugurar uma nova revolução cognitiva principalmente nas empresas, aconteceu à força. Reza a frase atribuída ao naturalista Charles Darwin, de que "Não é o mais forte que sobrevive, nem o mais inteligente, mas o que melhor se adapta as mudanças”. Que pode ser comprovado pela quantidade de empresas que encerraram suas atividades e o consequente incremento na taxa de desemprego em todo o globo, preconizando uma nova crise global, não só de saúde pública, mas principalmente econômica, onde todas as consequências pós pandemia ainda são desconhecidas (NEPOMUCENO, 2021).

Ainda sobre as tecnologias, Nepomuceno (202I) afirma que ao serem inventadas e disseminadas, elas permitem ao sapiens fazer o que até então era impossível, pouco provável, inacessível ou muito caro naquele momento. Elas ampliam nossos limites ainda intransponíveis e provocam o desejo de alcançá-los. Foi assim com a ida do homem a Lua e 
a criação da estação espacial, que a partir daí criou motivações para o homem ir a Marte e até explorar outras galáxias.

O papel da filosofia retoma assim o protagonismo histórico na construção do conhecimento, questionando o que no presente não é viável, é caro ou até impossível na visão da maioria. Inspirado pela estrutura das revoluções científicas de Kuhn (200o), Nepomuceno lembra que é imperioso mudar a forma de pensar a que fomos condicionados desde a infância.

Até então a análise de um problema se inicia na observação fenômeno ou problema, buscando uma experiência empírica ou operacional para a solução dele. Na ausência da solução neste segundo nível, passamos ao terceiro nível, que seria buscar métodos e conceitos já conhecidos para a solução, como se fosse uma base de conhecimentos restritos. Diante da aparente impossibilidade de resolver a questão, passamos ao quarto e último nível, que é a revisão dos conceitos teóricos e de toda literatura existente a respeito (NEPOMUCENO, 2021).

Confrontados com a falta de respostas efetivas para a solução do problema ou fenômeno observado, somos induzidos a acreditar que é impossível de resolvê-lo. Segundo Nepomuceno (202I), trata-se de um pragmatismo inadequado, onde procura-se rever a forma de agir, mas não a de pensar, ocasionando dificuldades como a baixa resiliência e a baixa competitividade em momentos de crises.

Se por outro lado, resolvemos o problema com o método atual, estamos diante de problemas conhecidos, pois os paradigmas atuais resolvem bem o problema operacional, e não é prático refletir ou questionar nossa antiga forma de pensar. No entanto, quando estamos diante de problemas desconhecidos, os paradigmas atuais não resolvem bem o problema operacional, tornando se extremamente prático e importante refletir sobre nossos antigos paradigmas para que tenhamos novos, mais adequados aos novos problemas e fenômenos (NEPOMUCENO, 2021).

Quando se propõe uma forma de pensar diferente, o pragmático inadequado foge de qualquer reflexão mais abstrata ou profunda, argumentando que é uma perda de tempo, já que o mais importante é colocar a "mão na massa". Eles não foram adequadamente 
apresentados as ideias de Kuhn (2000), que nos lembra que devemos variar nossa atitude diante de dois fenômenos:

No momento de normalidade, quando vale o pragmatismo, com revisões apenas incrementais e pontuais nas metodologias e no operacional, através do método indutivo, que considera paradigmas válidos para analisar os problemas. É quando os especialistas de determinados fatos e fenômenos conseguem, com toda segurança, antecipar e prever desdobramentos, não havendo necessidade de acionar nenhum alarme, pois basta a atualização incremental dos paradigmas vigentes. Neste caso, o pragmatismo está funcionando adequadamente.

Já no momento de anormalidade, vale a revisão dos paradigmas, com reflexão dos conceitos de forma radical ou disruptiva, através do método dedutivo, que considera que novos paradigmas analisam os problemas. É quando os especialistas de determinado fenômeno não conseguem com segurança antecipar e prever os desdobramentos do fenômeno analisado, então há a necessidade de acionar o alarme da anormalidade, pois a atualização incremental dos paradigmas vigentes não funciona mais. Os paradigmas existentes não estão mais válidos, o pragmatismo não está funcionando adequadamente e se mostra inadequado.

A contemporaneidade tem se mostrado um tempo de incertezas, de problemas complexos e inéditos, que transcendem o saber existente e questionam o conhecimento e as práticas comuns, tornando imperioso a adoção de um método mais identificado com o método dedutivo, onde abordamos os problemas e fenômenos a partir da especulação filosófica em direção a solução do problema (NEPOMUCENO, 2021).

\subsection{A REDE É O COMPUTADOR}

Black (2018) publicou no portal Insidehpc uma entrevista, em que retrata a saga de um estudante de Harvard, Scott McNealy, que fundou a empresa SUN micro systems para fabricar computadores que trabalhavam com uma variação do sistema operacional UNIX. Naquela época o slogan da empresa era "A rede é o computador". Isso na época não parecia fazer muito sentido, pois o que era conhecido como rede, eram computadores conectados 
entre si em um departamento, prédio ou no máximo em um campus. Tanto que o nome da empresa foi dado devido a uma rede local que fora construída na universidade de Stanford, a SUN - Stanford University Network. McNealy profetizou os dias atuais. Com uma rede de alta velocidade que interliga todos os computadores do mundo, a internet se tornou um grande computador.

Segundo o portal do Silicon Valley Historical Society, disponível em: https://www.siliconvalleyhistorical.org/silicon-valley-companies, acessado em 26 de abril de 2021, com a padronização do protocolo TCP/IP em 1982 e a invenção do roteador pela Cisco Systems em 1984, foi possível a interligação das várias redes entre si, ou seja, com este equipamento seria possível interligar geograficamente redes diferentes. Assim nasceu o que hoje seria a internet, mas em uma versão acadêmica que só pessoas muito especialistas poderiam acessar a rede. Em 1990 Tim Berners Lee criou o serviço World Wide Web e o primeiro navegador, habilitando qualquer indivíduo a acessar uma rede que já estava presente em várias localidades do mundo com um mínimo conhecimento técnico.

Friedman (2005), afirma que em 1986, com a adoção da fibra ótica para conexão de redes de longa distância em altas velocidades, a internet cresceu bastante e permitiu a adoção de novas aplicações, passando a trafegar além de dados, voz, imagens e vídeo. As fronteiras foram se ampliando e os cabos submarinos de fibra ótica passaram a interconectar continentes. Em 2005 o autor e jornalista do New York Times lançou o livro O Mundo é Plano apresentando a ideia de que devido as fibras óticas e as redes de alta velocidade, o mundo se tornou plano, já que um consumidor poderia ligar para a central de atendimento de uma empresa americana, mas a ligação seria atendida por um profissional localizado em Bangalore na Índia sem que este consumidor se desse conta disso, já que a ligação pareceria local de tão límpida.

Iniciava assim o que ficou conhecido como globalização e fomentou a terceirização de serviços que custavam caro em um determinado país, mas que poderiam ser prestados em outro com custos mais competitivos, com igual qualidade, independentemente da localidade física. Este fato impulsionou a logística internacional, tão importante para otimizar o comércio global de bens que passaram a ter suas partes produzidas em tempo real em 
diversos países e sendo enviadas para um único local onde o produto final seria montado e distribuído (FRIEDMAN, 2005).

Além do cabo de fibra ótica, Friedman (2005) elencou mais nove fatos que nivelaram o jogo global e foram fundamentais para tornar o mundo mais plano e conectado. A queda do muro de Berlim e o fim da guerra fria em 1989 incluiu os excluídos; O navegador Netscape em 1995 que popularizou a internet; $\mathrm{O}$ software de fluxo de trabalho, que permitiu a colaboração e o trabalho conjunto de pessoas em diversas geografias; A transferência de arquivos pela rede; O Offshoring, que levou operações ou partes de empresas para outros países mais competitivos e com melhores condições; Cadeia global de suprimentos, interligando todos os estoques; Insourcing, que permitiu que uma empresa com capacidade ociosa pudesse prestar serviços em nome de uma terceira; Os buscadores de informações na rede, como o Google e o Yahoo; e por fim os dispositivos móveis de computação conectados a rede sem fio, trafegando dados, voz e vídeo sobre IP.

Pierre Lévy (1993), filósofo francês especializado na compreensão das implicações culturais e cognitivas das tecnologias digitais e do fenômeno da inteligência coletiva humana, em sua obra Cibercultura de 1999, batizou o espaço digital existente entre os computadores ligados em rede que permite a troca de dados entre os usuários como Ciberespaço. Possui arquitetura aberta, pode crescer indefinidamente e inspirou o que chamamos hoje de nuvem elástica. A Cibercultura é um fluxo contínuo de ideias, práticas, representações, arquivos e colaborações que ocorrem entre pessoas conectadas por computadores,

\subsection{INSPIRADOS PELA FICÇÃO CIENTÍFICA}

Para Marasciulo (2018), Júlio Verne (1865), em sua obra Da Terra à Lua previu a chegada do homem a Lua, que ocorreria somente em 1969, utilizando um meio de transporte capaz de vencer a gravidade, que seria lançado de um determinado local, e que segundo as suas coordenadas geográficas, corresponderiam hoje ao local onde se encontra o cabo Canaveral. Preconizou ainda que este meio de transporte utilizaria propulsão baseada na luz, o que hoje conhecemos como Velas Solares. 
Verne (1870), em sua obra Vinte Mil Léguas Submarinas, retratou o submarino Nautilus, como um veículo movido a eletricidade. Mas na época, os veículos existentes eram movidos a vapor e os submarinos só surgiram anos depois. $\mathrm{O}$ mesmo ocorreu com o escafandro, relatado pelo autor como um reservatório de ar levado nas costas para habilitar o homem a permanecer por mais tempo embaixo da água.

Em I889, na estória O Dia De Um Jornalista Americano No Ano De 2889, versou sobre o que hoje conhecemos como jornais televisivos, podcasts e a videoconferência que se tornou comum após a pandemia. O seu phonotelephoto, hoje se assemelha ao nosso smartphone (JULES VERNE, I889).

Segundo Rollemberg (2015), Isaac Asimov, escritor russo, naturalizado nos EUA, serviu como químico na segunda guerra mundial, e publicou a sua primeira obra Eu Robô de 1950, considerado um clássico da ficção científica, onde narrou em nove histórias desde o desenvolvimento dos robôs até a dominação mundial (ASIMOV, 1950).

Posteriormente publicou mais quatro obras sobre robôs, onde criou e descreveu as três leis fundamentais da robótica: A primeira lei considera que um robô não pode ferir um ser humano ou, por inação, permitir que um ser humano sofra algum mal; A segunda lei define que um robô deve obedecer às ordens que lhe sejam dadas por seres humanos, exceto nos casos em que tais ordens entrem em conflito com a primeira lei; A terceira e última lei afirma que um robô deve proteger a sua própria existência desde que tal proteção não entre em conflito com a primeira ou segunda lei (ASIMOV, I950).

Asimov em 1976, escreveu O Homem Bicentenário, adaptado posteriormente, em 1999, para o cinema. Asimov acreditava no método científico como a melhor forma de compreender o universo natural desconsiderando mitologias, ou mesmo o conceito de céu e inferno. Suas crenças pessoais aproximavam-se mais do movimento humanista, pois não acreditava em influências sobrenaturais (ROLLEMBERG, 2015).

Alvin Toffler (1970), escritor americano e futurista renomado, iniciou seu trabalho discutindo tecnologias emergentes, revolução digital e das comunicações. Em sua primeira obra, o Choque do Futuro, retratou um futuro com sobrecarga de informações, onde seria produzido mais informações do que toda a humanidade produzira até então. Este fenômeno 
ocorreria principalmente devido a dinâmica das rápidas mudanças que afetariam a sociedade e derrubariam o processo tradicional de tomada de decisões (FUTURISMO, 2016).

Em A Terceira Onda, Toffler (1980) descreveu três tipos de sociedades, baseadas em ondas que transformariam a sociedade para sempre. Na primeira, tivemos a revolução da agricultura. Na segunda, tivemos a revolução industrial. A terceira desvelaria uma sociedade pós industrial, apoiada por transformações históricas e geopolíticas que culminaria na era da informação, a revolução digital e os avanços decorrentes dela.

Em Powershift, preconizou o incremento do poder militar no século XXI e a proliferação de tecnologias emergentes. Toffler (1990) nos exorta a contemplar, antecipar e agir sobre as extraordinárias mudanças econômicas, sociais e políticas no final do século XX. A evolução tecnológica seria apenas um sintoma de uma mudança de poder maior em todo o mundo. Esta mudança tiraria definitivamente o poder dos poucos que estão no topo, transferindo-o para os consumidores, trabalhadores e pequenos empresários (TOFFLER \& TOFFLER, 1995).

Raymond Kurzweil (2005), Inventor americano e futurista, em sua obra A Singularidade Está Próxima, afirma que a singularidade é o momento em que todos os avanços da tecnologia, particularmente na inteligência artificial, quando as máquinas serão mais inteligentes que os seres humanos. Segundo o autor, este processo já se iniciou e terá o seu cume em 2029, quando a Inteligência artificial passará em um teste de Turing válido. Em 2045, segundo o autor, multiplicaremos a nossa inteligência efetiva um bilhão de vezes, fundindo-nos com a inteligência que criamos (REEDY, 2017).

Para aqueles que veem essa sociedade cibernética como mais fantasia do que futuro, Kurzweil (2005) ressalta que "Há pessoas com computadores em seus cérebros hoje pacientes de Parkinson. É assim que a cibernética está apenas colocando o pé na porta”. E, como é da natureza da tecnologia melhorar, Kurzweil (2005) prevê que durante a década de 2030 alguma tecnologia será inventada que pode entrar em seu cérebro e ajudar sua memória. Então, em vez da visão de aquisição de máquinas da singularidade, o autor afirma que será um futuro de síntese homem-máquina incomparável. 
Peter Diamandis (2012), engenheiro e médico americano, em sua obra Abundância: O Futuro é Melhor do Que Você Imagina, retrata as potencialidades de um futuro próximo quando a inovação tecnológica exponencial permitirá que nove bilhões de pessoas terão acesso a água potável, saneamento básico, energia, internet, alimentos, educação e o que mais for necessário para um padrão de vida nunca alcançado pela humanidade. Este novo padrão não significa luxo, mas um futuro que proporcionará a todos uma vida de possibilidades.

Sua tese se apoia em quatro pilares. A primeira ideia é que nossas tecnologias de computação, energia, medicina e uma série de outras áreas estão melhorando a uma taxa tão exponencial que logo permitirão avanços que agora dificilmente imaginamos possíveis (DIAMANDIS, 2012).

O segundo, considera que essas tecnologias capacitaram os inovadores do tipo faça você mesmo a alcançar avanços surpreendentes - em engenharia de veículos, assistência médica e até biologia sintética - com recursos escassos e pouca mão de obra, de modo que podemos parar de depender de grandes corporações ou laboratórios nacionais (DIAMANDIS, 2012).

O terceiro pilar, afirma que a tecnologia criou uma geração de filantropos que estão despejando seus bilhões na solução de problemas aparentemente intratáveis, como fome e doenças (DIAMANDIS, 2012).

Finalmente, no quarto pilar, temos o que autor chama de "O bilhão em ascensão". Estes são os pobres do mundo, que agora graças à tecnologia são capazes de diminuir seus fardos de maneiras profundas. "Pela primeira vez, o bilhão em ascensão terá o poder notável de identificar, resolver e implementar suas próprias soluções de abundância" (DIAMANDIS, 2012).

Na obra O Novo Iluminismo, o cientista cognitivo Steven Pinker (2019) defende que a razão, a ciência e o humanismo são os ideais de que precisamos para enfrentar os nossos problemas e dar continuidade ao progresso. Ele incentiva o desprezo a manchetes alarmistas e profecias apocalípticas, que proliferam na contemporaneidade e influenciam a visão individual e coletiva de mundo. 
A partir de uma pesquisa muito bem organizada, Pinker (2019) demostra que a vida, a saúde, a prosperidade, a segurança, a paz, o conhecimento e a felicidade estão em ascensão, não apenas no Ocidente, mas em todo o mundo.

Para Pinker (2019), esse progresso é uma herança do Iluminismo: a convicção de que a razão e a ciência podem impulsionar o florescimento humano e, mais do que nunca, elas precisam de uma defesa vigorosa. Nadando contra as correntes da natureza humana exploradas por demagogos, o projeto iluminista é atacado por religiosos, políticos e intelectuais pessimistas que insistem que a civilização ocidental passa por um inexorável processo de declínio.

O resultado das pesquisas é indubitável. Basta olhar os dados: eles indicam que, com o avanço do conhecimento e da tecnologia, as pessoas estão de fato vivendo mais e melhor. Sem negar que nossos tempos são atribulados, Pinker (2019) não hesita em apontar o caminho para as soluções: reforçar o ideal iluminista de usar a razão e a ciência para resolver problemas.

\subsection{MÁQUINAS PENSANDO COMO HUMANOS}

Alan Turing, matemático, cientista da computação e filósofo britânico, considerado o pai da inteligência artificial, ficou conhecido internacionalmente como o decifrador da criptografia adotada pelos alemães em suas comunicações na segunda guerra mundial, o que permitiu com que os aliados pudessem derrotar os nazistas (COPELAND, 2006)

Em seu artigo Computer Machinery and Intelligence, Turing (1950) descreveu a hipótese: as máquinas conseguem pensar? Propôs então um teste hipotético para distinguir uma máquina de um ser humano, que ficou conhecido como o teste de Turing. Ele definiu um comportamento inteligente como sendo a habilidade de uma máquina alcançar um desempenho equivalente ou superior a um ser humano em todas as tarefas cognitivas, de forma a conseguir enganar os mais céticos.

O teste de Turing, segundo Shieber (2004) não conclui que as máquinas podem pensar, mas até que ponto elas podem ser confundidas com pessoas. Ele funciona da seguinte forma: Um interrogador humano fará perguntas a duas entidades ocultas. Uma delas é 
humana e a outra uma máquina. A comunicação entre eles deve ser feita através de um meio indireto, como um teclado por exemplo a fim de não permitir a distinção entre eles. $\mathrm{O}$ interrogador tentará conversar com as duas entidades para identificar qual das duas é a humana. A máquina está programada para se passar por humano. Se no final do teste o interrogador não conseguir distinguir quem é o humano, conclui-se então que o computador pode pensar.

Segundo o portal da Universidade do Texas em Austin, no centenário de Turing, em 2012 um grupo de pesquisadores da universidade fez uma máquina capaz de ser aprovada no teste de Turing. Um robô conseguiu convencer os juízes de uma competição de que era mais humano que a metade das pessoas com quem competiu. O grupo de pesquisadores levou cinco anos desenvolvendo e treinando algoritmos para atingir este resultado (THE UNIVERSITY OF TEXAS AT AUSTIN, 2012).

Inteligência artificial é a capacidade de um computador ou robô de executar tarefas comumente associadas a seres inteligentes. Segundo Russell (2003), o termo é frequentemente atribuído ao projeto de desenvolvimento de sistemas dotados dos processos intelectuais característicos dos seres humanos, como a capacidade de raciocinar, descobrir significado, generalizar e até aprender com a experiência passada.

Existem várias formas diferentes de aprendizagem aplicadas à inteligência artificial. O mais simples é aprender por tentativa e erro, e encontrado o que é certo, registrar esta solução na memória e utilizar esta experiência para resolver uma solução similar no futuro. A este processo se dá o nome de aprendizado rotineiro (RUSSEL, 2003).

Raciocinar é fazer inferências adequadas à situação. As inferências podem ser classificadas como dedutivas ou indutivas. A diferença mais significativa entre estas formas de raciocínio é que no caso dedutivo a verdade das premissas garante a verdade da conclusão, enquanto no caso indutivo, a verdade da premissa dá suporte a conclusão sem dar garantia absoluta (RUSSEL, 2003).

Para Muller (2020), a filosofia da inteligência artificial é uma área da filosofia da tecnologia que explora a inteligência artificial e suas implicações para o conhecimento e compreensão da inteligência, ética, consciência, epistemologia e livre arbítrio, sendo esta 
disciplina fundamental para os filósofos. Ela se propõe a resolver as seguintes perguntas: Uma máquina pode agir de forma inteligente? Pode resolver qualquer problema que uma pessoa resolveria pensando? A inteligência humana e a da máquina são iguais? $O$ cérebro humano é essencialmente um computador? Uma máquina pode ter mente, estados mentais e consciência no mesmo sentido que um ser humano pode? Pode sentir como as coisas estão?

Entre as modalidades da Inteligência artificial, a mais conhecida é o Aprendizado de Máquina, também conhecido como Machine Learning. Caracteriza-se pela capacidade dada aos computadores de melhorar progressivamente o desempenho de uma tarefa específica com dados, sem serem diretamente programados. Essa é a definição dada pelo cientista americano Arthur Lee Samuel. Ele cunhou o termo “aprendizado de máquina”, do qual existiam dois tipos, o supervisionado e não supervisionado. Recentemente, um terceiro tipo foi criado, o aprendizado por reforço, que retrataremos adiante ( $\mathrm{HOSCH}, 2020)$.

O Aprendizado de Máquina supervisionado acontece quando um programador pode fornecer um rótulo para cada entrada de treinamento no sistema. $O$ aprendizado não supervisionado ocorre quando o modelo é fornecido apenas com os dados de entrada, mas sem rótulos explícitos. Ele precisa pesquisar os dados e encontrar a estrutura ou os relacionamentos ocultos mesmo que o cientista de dados não saiba qual é a estrutura ou o que o modelo de aprendizado de máquina irá encontrar ( $\mathrm{HOSCH}, 2020)$.

O Aprendizado Profundo, ou Deep Learning, consiste em várias camadas de redes neurais, projetadas para executar tarefas mais sofisticadas. A construção de modelos de aprendizado profundo foi inspirada no design do cérebro humano, mas simplificada. Os modelos de aprendizado profundo consistem em algumas camadas de rede neural que são, em princípio, responsáveis por aprender gradualmente recursos mais abstratos sobre dados específicos ( $\mathrm{HOSCH}, 2020)$.

Embora as soluções de aprendizado profundo sejam capazes de fornecer excelente resultados, em termos de escala, elas não são páreo para o cérebro humano. Cada camada usa o resultado de uma anterior como entrada e toda a rede é treinada como um todo. O conceito central de criar uma rede neural artificial não é novo, mas apenas recentemente a capacidade computacional exponencial tornou-se suficiente para treinar efetivamente essas redes, 
expondo um número suficiente de exemplos, e permitindo a sua utilização em aplicações até então inéditas ( $\mathrm{HOSCH}, 2020)$.

Conforme a Data Science Academy explica em seu portal deep learning book, capítulo 62, o Aprendizado Por Reforço, ou Reinforcement Learning, emprega um sistema de recompensas e penalidades para obrigar o computador a resolver um problema sozinho. $\mathrm{O}$ envolvimento humano é limitado à mudança do ambiente e ao ajuste do sistema de recompensas e penalidades. Como o computador maximiza a recompensa, ele está propenso a procurar maneiras inesperadas de fazê-lo.

O envolvimento humano é focado em impedir que ele explore o sistema e motive a máquina a executar a tarefa da maneira esperada. O aprendizado por reforço é útil quando não existe uma "maneira adequada" de executar uma tarefa, mas existem regras que o modelo deve seguir para desempenhar corretamente suas tarefas.

De acordo com o problema a ser resolvido, a aplicação do aprendizado por reforço pode incorrer em questões éticas e de discriminação algorítmica, uma vez que para se atingir os resultados (fins), os meios para atingi-los podem se justificar sem necessariamente considerar quaisquer ponderações, regras ou referências do que seria certo ou errado em dada situação. Este seria mais um problema a ser tratado pelo profissional de filosofia (KEARNS, 2019).

\subsection{A ÉTICA E MORAL DAS MÁQUINAS}

Para Timm et al. (2007) a ética computacional, ou ética da Inteligência Artificial considera uma dinâmica baseada em técnicas, valores e princípios aceitos como certo ou errado para nortear a conduta moral no desenvolvimento de algoritmos de inteligência artificial.

Com a diversidade e necessidade de inclusão social de pessoas desfavorecidas economicamente, de características diferentes ou componentes de grupos minoritários, torna-se imperioso que a inteligência artificial saiba tratar estes problemas a fim de evitar qualquer tipo de discriminação (BAER, 2019). 
O viés algorítmico, ou discriminação algorítmica, segundo Kearns (2019), é uma anomalia na saída dos algoritmos de inteligência artificial que podem ser provocados por superposições preconceituosas feitas no desenvolvimento ou no treinamento do mesmo. São erros sistemáticos que criam resultados injustos, como privilegiar um grupo em detrimento de outro ou negar um empréstimo a um cliente qualificado devido a suas limitações físicas.

Para Baer (2019), um dilema ético que necessita ser tratado com frequência é o uso de assistentes virtuais para atendimento automático de clientes, também conhecidos como Bots. Segundo Muller (2016) e Cano (2016), o caso mais conhecido é o da Tay, assistente virtual da Microsoft, que em 2016 foi corrompida em menos de 24 horas e passou a pregar ódio a minorias em mensagens automáticas no Twitter, e até incentivar suicídios, sublimando os perigos que a IA pode ocasionar quando mal programada ou implementada sem as necessárias reflexões sobre os dilemas éticos e suas consequências.

Um outro caso recente, reportado por Lacsko (202I) envolve a assistente virtual do banco Bradesco, a Bia. A jornalista afirma que supostamente devido ao seu mal funcionamento, a Bia irritava os clientes, que por consequência dispensavam impropérios e ofensas a assistente virtual. Em vez do banco utilizar os eventos para resolver os problemas e tornar a experiência dos clientes mais rica e interativa, preferiu mudar o viés do problema, investindo em uma campanha publicitária que destacava o quanto pior o ser humano pode ser. Culpou alguns de seus clientes pelas ofensas deferidas à Bia, sem tomar qualquer ação afirmativa para defender as milhares de mulheres que passam por situações de assédio ou violência na vida real.

As questões aqui expostas podem ser amplificadas devido a uma tendência social de posições extremas, mas ao mesmo tempo superficiais. O sociólogo polonês Zygmunt Bauman (200I) desenvolveu o conceito de modernidade líquida, que diz respeito a uma nova época em que as relações sociais, econômicas e de produção são frágeis, fugazes e maleáveis como os líquidos. Vivemos hoje esta época, que se opõe ao conceito de modernidade sólida, do mesmo autor, que desvela uma época anterior onde as relações eram solidamente estabelecidas, tendendo a serem mais fortes e duradouras. 


\section{CONSIDERAÇÕES FINAIS}

Drucker (1993), o pai da administração moderna definiu claramente a migração do trabalho braçal, que atingiu seu auge no fim do século passado, para o trabalho baseado no conhecimento intenso. $O$ novo século seria regido por um novo modelo econômico de prosperidade: A sociedade do conhecimento. Um bem não seria mais valorado somente pelo material e mão de obra empregado nele, mas principalmente pelo seu conhecimento tecnológico intrínseco. Hoje um programa de computador pode valer mais do que um avião. Esta sociedade se caracteriza pela produção do trabalho intensivo em conhecimento.

A partir da filosofia, os conceitos de ética e moral foram se construindo, se fortalecendo e se ajustando às necessidades das respectivas épocas para tornar a vida melhor e a convivência de forma civilizada. A busca pela solução dos problemas vigentes nos levou as ciências, e por consequência, o renascimento e as inovações, que resolveram grandes problemas da humanidade, principalmente nas áreas de saúde, educação, alimentação, artes, saneamento, bem estar, entre outras.

A tecnologia, que caracteriza a espécie humana e seu progresso, resolve muitos problemas, como uma boa ferramenta, mas também traz alguns outros que necessitam ser adequadamente pensados e tratados. A computação, a Internet e as transformações sociais dos novos tempos tornaram as distâncias físicas irrelevantes e a comunicação ubíqua, trazendo uma cibercultura, que permeia o intercâmbio de povos, ideias e colaboração, como só vimos antes nos portos da Grécia na antiguidade.

Verne, Asimov, Toffler, entre outros escritores de ficção científica, hoje futurólogos, preconizaram precisamente os momentos presentes ou que estão próximos de acontecer. $\mathrm{O}$ que era impossível, já não parece mais ser. As fronteiras da ciência são expandidas quase diariamente por inovações ou necessidades latentes, modificando a estrutura das revoluções científicas.

A adoção massiva de novas tecnologias pela sociedade, sobretudo a inteligência artificial, vem pressionando o que se foi pensado até agora sobre ética e moral. A proximidade da Singularidade Tecnológica e o aumento exponencial da capacidade computacional, pode proporcionar uma vida de abundância e benefícios, ou não. 
Torna-se imperioso construir uma nova edificação do conhecimento, baseado na especulação filosófica para ponderar o que pode ser considerado certo ou errado ou bom e ruim para a sociedade. Não podemos deixar as máquinas resolverem estes dilemas com algoritmos que estão orientados ao fim, desconsiderando os meios, os impactos e as suas consequências para a humanidade e para a preservação dela.

O filósofo passa a ser um profissional indispensável para refletir, orientar, questionar, mitigar e lidar com situações que envolvem não somente a dinâmica ética e moral computacional, mas principalmente os dilemas provenientes das interações entre o homem e as máquinas. Seu trabalho é fundamental para apoiar programadores, engenheiros e cientistas de dados a criarem algoritmos éticos que possam privilegiar a equidade em detrimento da igualdade e equacionar corretamente os conceitos do que seria certo, errado ou inconcebível. Suas ações devem considerar o impacto social e ambiental, as dimensões éticas e morais neste novo cenário cibernético e desenvolver a abstração necessária para lidar com os problemas da complexidade demográfica progressiva.

Devemos utilizar as melhores habilidades que a tecnologia dispõe para trazer sentido a vida, fazendo a interação entre os homens e as coisas mais humana, natural, cognitiva, sustentável e socialmente responsável. Deixemos as máquinas fazerem o que elas fazem melhor que nós para que tenhamos mais qualidade de vida, mais tempo para olhar nos olhos, segurar na mão, entre outras coisas belas, singelas e idiossincrasias que nos diferenciam das máquinas, mas que deixamos de perceber devido a pressão diária do cotidiano.

A despeito do pessimismo onipresente e a polarização maniqueísta difundida no noticiário, dados e estudos apontam que estamos próximos de um provável novo Iluminismo. Este seria o momento em que bilhões de pessoas disporão de um estado bem estar social até então inédito na humanidade. Com a física quântica, o que era binário, passou a dispor de inúmeras possibilidades e não nos deixa razão para pensar em extremos. Equidade, justiça, inclusão, diversidade entre outros valores sociais desejáveis podem nos levar a um novo contrato social e um provável novo modelo econômico. $O$ Antropocentrismo que outrora impulsionou as transformações cognitivas, deu lugar ao Biocentrismo, já que o homem não existe sem a natureza. 
Concluo afirmando que o professor de Filosofia não está mais condicionado à sala de aula, mas estimulado a estender a sua prática a um campo de trabalho mais abrangente. Com a chegada de novas profissões, o desenvolvimento contínuo é o novo devir, passou a ser um mantra e o filosofar, o prana. $\mathrm{Na}$ sociedade do conhecimento, o filósofo volta a ter uma importância provavelmente maior do que já teve no Zeitgeist da modernidade, quando tudo partia da filosofia para se explicar qualquer fenômeno. Mesmo tendo que se passar pela ciência, ela sempre foi o princípio de tudo.

A filosofia retoma o protagonismo histórico na construção do conhecimento e para ajudar a resolver os problemas que não parecem factíveis, constituindo assim uma dinâmica das impossibilidades e a necessidade de uma ciência da inovação. Sua nova função não se limita a lidar e entender os pontos em comum entre a tecnologia e a sociedade, mas principalmente mitigar e mediar conflitos entre a inteligência das coisas e a consciência humana, tornando a vida mais significativa e menos complexa em tempos de modernidade líquida e de gerações superficiais.

Os direitos humanos são inalienáveis. Eles nos distinguem das coisas. Talvez seja inevitável constituir um "direito das coisas" para evitar um futuro niilismo. Penso que sem reflexão não haverá salvação para a humanidade, quiçá para as máquinas.

\section{REFERÊNCIAS}

ARISTÓTELES. Ética a Nicômaco. Tradução Leonel Valandro e Greg Bornheim. São Paulo: Nova Cultural, 1987. (Os Pensadores). Tradução de: Ethics.

ASIMOV, Isaac. I, Robot. Garden City, NY: Doubleday, 1950. 304 p.

BACON, Francis. Novum Organum: Verdadeiras Indicações Acerca da Interpretação da Natureza. Tradução José Aluysio Reis de Andrade. Abril Cultural, v. XIII, 1976. 278 p. (Os Pensadores). Tradução de: Pars secunda operisquae dicitur novum organum sive indicia vera de interpretatione naturae.

BAER, Tobias. Understand, Manage, and Prevent Algorithmic Bias: A Guide for Business Users and Data Scientists. Apress, f. 123, 2019. 245 p. 
BAUMAN, Zygmunt. Modernidade líquida. Rio de Janeiro: Editora Schwarcz Companhia das Letras, f. 129, 200I. 258 p.

BLACK, Doug. Video: Scott McNealy on Why the Network is Still the Computer. Inside HPC magazine. 2018. Disponível em: https://insidehpc.com/2018/o5/video-scottmcnealy-network-still-computer/. Acesso em: 26 abr. 2021.

BURCKHARDT, Jacob. A cultura do Renascimento na Itália: um ensaio. São Paulo: Cia das Letras, 2009.

CANO, Rosa Gimenez. O robô racista, sexista e xenófobo da Microsoft acaba silenciado: Projetado para o mercado dos 'millennials' nos Estados Unidos, Tay não foi capaz de lidar com piadas e perguntas controvertidas. El Pais. 2016. Disponível em:

https://brasil.elpais.com/brasil/2016/o3/24/tecnologia/I458855274_096966.html. Acesso em: 24 abr. 2021.

COPELAND, B. Jack. Colossus: The secrets of Bletchley Park's code-breaking computers. Oxford University Press, f. 240, 2006. 48o p.

CUPANI, Alberto. Filosofia da Tecnologia: Um Convite. 3. ed. Florianópolis: Editora UFSC, 20II.

DATA SCIENCE ACADEMY. O que é aprendizado por reforço?: Cap. 62. Deep Learning Book. Disponível em: https://www.deeplearningbook.com.br/o-que-eaprendizagem-por-reforco/. Acesso em: 6 mar. 2021.

DESCARTES, René. Discurso do Método. Tradução J. Guinsburg e Bento Prado Júnior. Abril Cultural, v. XV, 1973. 79 p. (Os Pensadores). Tradução de: Discours de la méthode de bien conduire sa raison et chercher la vérité dans les sciences.

DIAMANDIS, Peter H.; KOTLER, Steven. Abundance: The Future Is Better Than You Think. Simon and Schuster, f. 216, 2012. 432 p.

DRUCKER, Peter F.. Post-Capitalist Society. Butterworth-Heinemann, f. I06, 1993. 212 p.

EMPRESAS do Vale do Silício: Uma Breve história. Silicon Valley Historical Society. Disponível em: https://www.siliconvalleyhistorical.org/silicon-valley-companies. Acesso em: 26 abr. 2021. 
FRIEDMAN, Thomas L.. World Is Flat: : A Brief History of the Twenty-First Century. New York: Farrar, Straus and Giroux, 2005.

FUTURISMO: As Ideias de Alvin Toffler. Revista Exame. 20I6. Disponível em: https://exame.com/negocios/futurismo-as-ideias-de-alvin-toffler/. Acesso em: I mai. 2021.

HEGEL, Georg Wilhelm Fredrich. Elements of the Philosophy of Right. Cambridge University Press, v. I, f. 257, 1991. 514 p.

HOBBES, Thomas. Leviatã: Matéria, forma e poder de um estado eclesiástico e civil. Tradução João Paulo Monteiro e Maria Beatriz Nizza. Abril Cultural, v. XIV, 1974. 423 p. (Os Pensadores). Tradução de: Leviathan, or Matter, Form and Power of a Commonwealth Ecclesiastical and Civil.

HOSCH, William L.. Machine learning. Encyclopedia Britannica. 2020. Disponível em: https://www.britannica.com/technology/machine-learning. Acesso em: 25 abr. 202I.

JONAS, Hans. Technology and Responsability: Reflections on the New Task of Ethics. Social Research, v. 15, Spring 1973.

KANT, Immanuel. Fundamentação Da Metafísica Dos Costumes. Tradução Paulo Quintela. São Paulo: Abril Cultural, v. XXY, i974. 196 p. (Os Pensadores). Tradução de: Grundlegung zur Metaphysik der Sitten.

KEARNS, Michael; ROTH, Aaron. The Ethical Algorithm: The Science of Socially Aware Algorithm Design. Oxford University Press, USA, f. II6, 2019. 232 p.

KUHN, Thomas S.. A estrutura das revoluções científicas. São Paulo: Editora Perspectiva S.A., 2000. 324 p.

KURZWEIL, Ray. The Singularity Is Near: When Humans Transcend Biology. Penguin, v. 2, f. 336, 2005. 672 p.

LACSKO, Madeleine. Bia do Bradesco : inteligência artificial capenga importa mais que as clientes. Gazeta do Povo. Internet, 2021. Disponível em:

https://www.gazetadopovo.com.br/vozes/madeleine-lacsko/bia-do-bradesco-inteligenciaartificial-capenga-importa-mais-que-as-clientes/. Acesso em: 20 abr. 202I. 
LÉVY, Pierre. As Tecnologias da Inteligência: O Futuro do Pensamento na Era da Informática. Rio de Janeiro: Editora 34, 1993. 203 p.

LÉVY, Pierre. Cibercultura. Rio de Janeiro: Editora 34, 1999. 264 p.

MACHIAVELLI, Nicolao. Il príncipe. Oxford Clarendon Press, i89I.

MARASCIULO, Marilia. Júlio Verne: previsões do autor que se tornaram realidade. Revista Galileu, https://revistagalileu.globo.com/Cultura/noticia/2018/o3/julio-verneprevisoes-do-autor-que-se-tornaram-realidade.html, 2018.

MULLER, Léo. Tay: Twitter conseguiu corromper a IA da Microsoft em menos de 24 horas. Tecmundo. 2016. Disponível em: https://www.tecmundo.com.br/inteligenciaartificial/ro2782-tay-twitter-conseguiu-corromper-ia-microsoft-24-horas.htm. Acesso em: 29 mar. 2021.

MÜLLER, Vincent C.. Ethics of Artificial Intelligence and Robotics. Stanford Encyclopedia of Philosophy. 2020. Disponível em: https://plato.stanford.edu/archives/winzo2o/entries/ethics-ai/. Acesso em: 3 abr. 202I.

NEPOMUCENO, Carlos. Civilização 2.0: Por que estamos sendo obrigados a imitar as formigas?. 3. ed. Rio de Janeiro: Bimodais - Futurismo competitivo, 202I. 26I p.

NEPOMUCENO, Carlos. Curadoria Digital. Rio de Janeiro: Alta books, 2016. I5ı p.

NEWTON, Isaac. Principia : Princípios Matemáticos de Filosofia Natural . Tradução Carlos Lopes de Mattos e Pablo Mariconda. São Paulo: Abril Cultural, v. XIX, 1974. (Os Pensadores). Tradução de: Philosophiae Naturalis Principia Mathematica.

PINKER, Steven. Enlightenment Now: The Case for Reason, Science, Humanism, and Progress. Penguin Books, v. 2, f. 128, 2019. 256 p.

PLATÃO. Protágoras. Tradução Ana Piedade Elias Pinheiro. Lisboa: Relógio D'agua, 1999.

REEDY, Christianna. Kurzweil Claims That the Singularity Will Happen by 2045: Get ready for humanity 2.0.. Futurism Magazine. 2017. Disponível em: https://futurism.com/kurzweil-claims-that-the-singularity-will-happen-by-2045. Acesso em: 25 abr. 2021. 
ROLLEMBERG, Thaciane. Isaac Asimov. InfoEscola. 2015. Disponível em: https://www.infoescola.com/escritores/isaac-asimov/. Acesso em: I mai. 202I.

ROUSSEAU, Jean-Jacques. Do contrato social: Princípios do Direito Político. Tradução Pietro Nassetti. São Paulo: Martin Claret, 2006. I20 p. (A Obra Prima de Cada Autor). Tradução de: Du Contrat Social.

RUSSELL, Stuart J.; NORVIG, Peter. Artificial Intelligence: A Modern Approach. 2. ed. New Jersey: Prentice Hall, f. 566, 2003. II32 p.

SHIEBER, Stuart M.. The Turing Test: Verbal Behavior as the Hallmark of Intelligence. New York: Penguin Books, 2004.

SINGER, Peter. Ética. Enciclopédia Britannica. Disponível em: https://www.britannica.com/topic/ethics-philosophy. Acesso em: 24 abr. 202I.

SPINOZA, Baruch. ÉTICA: Demonstrada à Maneira dos Geômetras. Tradução Joaquim de Carvalho. São Paulo: Abril Cultural, v. XVII, 1973. (Os Pensadores). Tradução de: Ethica.

THE UNIVERSITY OF TEXAS AT AUSTIN. Artificially Intelligent Game Bots Pass the Turing Test on Turing's Centenary. UT News. Austin, Texas, USA, 2012. Disponível em: https://news.utexas.edu/2012/o9/26/artificially-intelligent-game-bots-pass-theturing-test-on-turings-centenary/. Acesso em: 17 abr. 202I.

TIMM, Maria Isabel et al. A virada computacional da filosofia e sua influência na pesquisa educacional. Pepsic - CIência \& Cognição, Rio de Janeiro, v. II, Julho 2007. Disponível em: http://pepsic.bvsalud.org/scielo.php?script=sci_arttext\&pid=Sı8o6582,12007000200002\&lng=pt\&nrm=iso. Acesso em: 25 abr. 2021.

TOFFLER, Alvin. Future Shock. New York: Random House, f. 312, 1970. 624 p.

TOFFLER, Alvin. Powershift: Knowledge, Wealth, and Violence at the Edge of the 2ist Century. New York: Bantam Books, f. 306, 1990. 6ir p.

TOFFLER, Alvin. The Third Wave. New York: Morrow, f. 272, 1980. 543 p.

TOFFLER, Alvin; TOFFLER, Heidi. Creating a New Civilization: The Politics of the Third Wave. New York: Turner Pub, f. 56, 1995. I12 p. 
TURING, Alan M.. Computing Machinery and Intelligence: Great Papers Philosophie. Reclam Verlag, v. 3, f. I0I, I950. 202 p.

VERNE, Jules. From the Earth to the Moon and 'Round the Moon.

https://www.gutenberg.org/ebooks/83, I865.

VERNE, Jules. La Journée d'un journaliste américain en 2890.

https://www.futuribles.com/fr/revue/310/la-journee-dun-journaliste-americain-en-2890/, I889.

VERNE, Jules. Vingt Mille Lieues Sous Les Mers.

https://www.gutenberg.org/ebooks/164, I870. 